\title{
Práticas corporais e meditativas na promoção da saúde: um desafio interdisciplinar, multiprofissional e intersetorial
}

\author{
Bodily and meditative practices in health \\ promotion: an interdisciplinary, multiprofessional \\ and intersectorial challenge
}

\author{
Prácticas corporales y meditativas en \\ la promoción de la salud: un desafío \\ interdisciplinario, multiprofesional e \\ intersectorial
}

\author{
Ana Tereza Costa Galvanese 1 \\ Nelson Filice de Barros 2 \\ Ana Flavia Pires Lucas d'Oliveira 1
}

doi: $10.1590 / 0102-311 \times 00112418$

No contexto sociocultural contemporâneo, o destaque ocupado pela temática do corpo está posto e recebe atenção tanto das políticas públicas quanto do mercado, que lhe revertem investimentos, modelos e receitas para um corpo ideal. Cabe perguntar: o que diferencia pode, ou mesmo deve, diferenciar as abordagens do corpo no âmbito das políticas públicas?

Buscar respostas a essa questão requer um amplo debate, com a contribuição de múltiplos atores; e, por isso mesmo, são bem-vindos os questionamentos apresentados por Rogério Cruz de Oliveira em Práticas Corporais e Meditativas: Educação Física à Margem?. O autor discute a participação dessa categoria profissional no contexto do artigo Contribuições e Desafios das Práticas Corporais e Meditativas à Promoção da Saúde na Rede Pública de Atenção Primária do Município de São Paulo, Brasil 1, que analisa essas práticas com base em um recorte bem delimitado e preciso: o observado e o informado por sujeitos de pesquisa, em serviços de atenção primária do Sistema Único de Saúde (SUS) do Município de São Paulo, Brasil.

O foco do artigo foi a análise das relações entre as características das práticas corporais e meditativas observadas naquele contexto, desempenhadas por profissionais de várias formações e orientadas por diferentes racionalidades de saúde, conhecimentos e tradições culturais, e a promoção da saúde dos praticantes. Essa perspectiva, que implica compromisso com a lógica inclusiva da complementaridade, configurou-se também nas escolhas teóricas e metodológicas do estudo.

Assim, coube-nos destacar, mais do que as diferenças entre as racionalidades e abordagens que compõem essas práticas, os seus pontos em comum, constatados nos modos de cuidar, quais sejam: a oferta de oportunidades de construção de referências vivenciais no cuidado à saúde; a sinergia entre promoção da saúde e cuidado terapêutico; e a sintonia com uma perspectiva ampliada de saúde, traduzida na valorização da autonomia dos sujeitos em seus modos de vida e no apoio à ampliação de suas redes de sociabilidade e convivência cidadã.

Embora se saiba de antemão que, na formação profissional, os conhecimentos não são estanques, rígidos ou isolados e que, mesmo dentro de cada profissão da saúde, há diferentes visões e concepções de cuidado, nossa análise revelou que as abordagens adotadas por diferentes profissionais não vieram majoritariamente das suas formações acadêmicas e escolares, mas sim de convergências delas com a formação complementar, seja custeada individualmente ou como parte da educação continuada, oferecida pelos serviços, no âmbito do SUS.
1 Faculdade de Medicina Universidade de São Paulo, São Paulo, Brasil.

2 Faculdade de Ciências Médicas, Universidade Estadual de Campinas, Campinas, Brasil.

\section{Correspondência} A. T. C. Galvanese Departamento de Medicina Preventiva, Faculdade de Medicina, Universidade de São Paulo.

Av. Dr. Arnaldo 455, São Paulo, SP 01246-903, Brasil. anagalvanese@usp.br 
Ao se priorizar a análise das convergências na formação dos profissionais, pôde-se averiguar o quão incipiente é a presença das práticas corporais e meditativas na formação das diversas profissões da saúde. Esse achado de pesquisa corrobora a percepção de que, para se alcançar a legitimação do trabalho com essas práticas no SUS, caminhos precisam ser construídos pelo vasto elenco das profissões de saúde que aí atuam, sem hierarquias. Nesse sentido, a participação dos educadores físicos é importante, assim como a das diferentes profissões de saúde que abordam o corpo mediante seus referenciais de cuidado.

Nessa perspectiva, a construção conjunta de caminhos de legitimação das práticas corporais e meditativas na saúde comporta pelo menos três dimensões: a interdisciplinaridade, a multiprofissionalidade e a intersetorialidade.

A dimensão interdisciplinar está expressa na concepção original da Política Nacional de Práticas Integrativas e Complementares (PNPIC), no compromisso com a integralidade da atenção à saúde e interação de ações e serviços existentes no SUS. No entanto, é necessário analisar em que medida tal premissa está ameaçada pelo atual descompasso entre a introdução de novas práticas e a carência de parâmetros técnicos, essenciais aos processos de acompanhamento, avaliação e formação de recursos humanos 2,3.

O trabalho multiprofissional é um desafio para a formação dos profissionais de saúde, predominantemente uniprofissional, disciplinar e corporativa. Na reversão dessa tendência, é preciso adotar a educação interprofissional em saúde articulada a práticas em serviços de atenção primária, combinando os aprendizados específicos de cada área profissional com a preparação para o trabalho coletivo ${ }^{4}$. A formação para o trabalho com práticas corporais e meditativas nesse modelo é uma possibilidade ainda pouco explorada.

A construção da intersetorialidade é essencialmente coletiva, com desafios no campo do fazer relacionados, em diversos planos, ao diálogo e à parceria entre os vários atores sociais 5 . No plano mais imediato, a presença, em um mesmo território, de práticas corporais e meditativas similares, oferecidas em equipamentos sociais diferentes, exemplifica a fragmentação que se pretende superar; ao mesmo tempo, possibilita indagar acerca do protagonismo dos atores envolvidos, seja na produção de espaços de interlocução, seja na articulação de parcerias.

Em suma, para que as práticas corporais e meditativas contribuam de forma mais significativa à promoção da saúde, é essencial o compromisso dos seus atores com um diálogo que possa desenhar novos horizontes para esse saber-fazer, compartilhando e trazendo à discussão questões que são caras a esse universo de práticas como, por exemplo, o tema da corporeidade. 


\section{Colaboradores}

A. T. C. Galvanese, N. F. Barros e A. F. P. L. d'Oliveira colaboraram na concepção, redação e revisão do texto.
1. Galvanese ATC, Barros NF, d'Oliveira AFPL. Contribuições e desafios das práticas corporais e meditativas à promoção da saúde na rede pública de atenção primária do Município de São Paulo, Brasil. Cad Saúde Pública 2017; 33:e00122016.

2. Departamento de Atenção Básica, Secretaria de Atenção à Saúde, Ministério da Saúde. Política Nacional de Práticas Integrativas e Complementares no SUS: atitude de ampliação de acesso. 2a Ed. Brasília: Ministério da Saúde; 2015.

3. Ministério da Saúde. Portaria no 702 , de 21 de março de 2018. Altera a Portaria de Consolidação no 2/GM/MS, de 28 de setembro de 2017, para incluir novas práticas na Política Nacional de Práticas Integrativas e Complementares - PNPIC. Diário Oficial da União 2018; 22 mar.

4. Silva JAM, Peduzzi M, Orchard C, Leonello VM. Educação interprofissional e prática colaborativa na Atenção Primária à Saúde. Rev Esc Enferm USP 2015; 49(Esp 2):16-24.

5. Mendes R, Akerman M. Intersetorialidade: reflexões práticas. In: Fernandez JAC, Mendes R, organizadores. Promoção da saúde e gestão local. 2a Ed. São Paulo: Editora Hucitec/Cepedoc; 2014. p. 85-110.

Recebido em 08/Jun/2018

Aprovado em 13/Jun/2018 